\title{
AN EXPLORATORY STUDY OF ADOPTION OF INFORMATION TECHNOLOGY BY SMALL AND MEDIUM BUSINESSES
}

\author{
Utpal Bose, University of Houston Downtown, boseu@uhd.edu
}

\begin{abstract}
Since small and medium businesses constitute the vast majority of businesses in our economy and the most number of jobs that go with it, it is necessary for those businesses to become more innovative and competitive through the use of information technology (IT). Given that a multitude of business drivers and factors can influence the adoption of IT by small and medium businesses, it is important to investigate the multidimensional nature of the factors and barriers to help these businesses realize what they are doing right and what is holding them back from becoming more innovative and competitive through use of IT. This study adds to the body of knowledge on adoption of IT by small and medium businesses by proposing a research model that focuses on the impact the firms' quality orientation, efficiency consciousness, availability of resources, and selected CEO characteristics can have on its IT investments. The research model is being validated through a questionnaire-based survey, which is in progress now. Therefore, this study is a work-in-progress. Currently data has been collected and preliminary data analysis has been done and reported here. When completed, the study is expected to provide valuable insights to important and common barriers faced by small businesses in adopting IT thus helping them to realize how to move forward to become more competitive and innovative.
\end{abstract}

Keywords: Information Systems; Information and Communications Technologies; Small and Medium Enterprises (SMEs); Information Technology Adoption

\section{INTRODUCTION}

The small and medium businesses play a pivotal role in the nation's economy. Small and medium enterprises (SMEs) account for over $97 \%$ of all businesses, approximately $50 \%$ of the GDP and over half of the employment in the United States (Ramsey et al 2009). Generally, SMEs adapt to changing business environments and innovate to overcome challenges faster than larger enterprises, while being quick to change directions if the economic conditions change. However, it is difficult to retain these capabilities more and more without the adoption of information and communications technologies (ICT) to support their business processes. It has been often said that ICTs empower SMEs to overcome the competitive disadvantages they face due to small size, limited resources, geographical locations, and access to market. In spite of the potential benefits of ICT, research has found that the adoption and use of these technologies has been challenging and slow.

It is pertinent to comment on the use of the term small and medium enterprises compared to using just small enterprises. While a business entity's size standards have been established for types of economic activity, or industry by the North American Industry Classification System (NAICS), when the Small Business Administration (SBA) in the United States defines small business by the number of employees, it often refers to those with fewer than 500 employees ("Summary of Size Standards by Industry - SBA.gov", 2011). Even though the SBA does not consider medium sized businesses in its size standards, the vast majority of published literature uses the term small and medium enterprises (SME) to refer to this size of business entities. An added advantage of using the term SME is that it consolidates the varying size definitions for small business used in countries across the world. In this paper, we use the terms small and medium enterprises and just small businesses interchangeably but our focus remains on business entities that employ 500 or less employees.

Several research studies have been done in relation to adoption of ICT by small and medium enterprises (SMEs) in the last decade and earlier. Broadly, the studies examine issues and challenges in information technology (IT) use by SMEs (Burgess 2002; Caldeira and Ward 2002; Matthews 2007; Wolcott et al 2007; Huang et al 2004; Tan et al 2010) and adoption of web-based business systems by SMEs (Raymond et al 2005; Xu et al 2007; Wymer and Regan 2005) along with other useful studies such as adoption of wireless LAN by SMEs (Anderson and Schwager 
2003). Most of theses studies are exploratory and investigate the issues involved in the adoption process of technology using surveys and interviews. Most of the studies developed various hypotheses about the possible obstacles in adoption of IT and tested them using various models. A large number of variables have been used in these studies and it has been difficult to draw consistent inferences due to variation in naming, grouping, and interrelating the variables (Huang et al 2004). Also, any extrapolation of the findings has been difficult due to the differences in demographic characteristics such as industry sector, country of operation, ethnicity, maturity of market, and infrastructure. In spite of growing number of research studies in this area, the findings remain clouded.

Whether to invest in IT and to what extent has always been a difficult decision to make in businesses of all sizes. But it becomes more difficult in small businesses where many owner-managers apply their personal financial assets to the business, making them extra cautious about investing in IT in comparison to other needed resources of their business. Most of the research in IT investment has been primarily outcome focused, that is, it concentrates on the consequences of IT investments, particularly with regard to value and success, performance, and impacts both within the organization and between organizations, rather than explaining the nature of these investments and what influences firms to make these investments. Moreover, much of the theories linking IT and performance offered in the literature have been studies in large firms, the results of which cannot be generalized to small businesses (Proudlock 1999). Considering that investing in IT by small businesses has been studied little, it is important to explore IT investment in small businesses. Our study develops a series of propositions related to the multidimensional nature of IT investments and their relationship with several antecedents, firm's quality orientations, their desire to improve internal efficiency, organizational resources and commitment, governmental influence and the competitive climate, followed by testing the propositions in the context of small US firms. This paper reports a work in progress in which the propositions have been developed, the survey instrument has been constructed and validated, and data has been collected. Data analysis is in progress. Using the initial analysis of data, we present some summary statistics.

\section{LITERATURE REVIEW}

The common reasons for most firms to adopt IT are to improve their ability to survive and grow, stay competitive and to be able to innovate (Burca et al 2005; Bruque and Moyano 2007). SMEs, however, adopt IT for a variety of reasons including those above because they can function in varying ways in different environments (Macpherson et al 2003), and they do not necessarily operate in the same way or have the same inpact (Oakey and Cooper 1991). What drives to acquire or improve IT is a purpose to satisfy certain requirements or to respond to necessary improvements, which could arise from pressures from internal and external sources. Such sources could be pressure from customers and an emphasis on improving efficiency (Corso et al 2003), life cycles effects or maturity of the firm (Siggelkow and Levinthal 2005), technology-push of innovations that are well developed and the consequent pressure from the market to absorb it (Andries and Debackere 2006), and the pressure to gain competitive advantage which may also be a result of being influenced by a combination of various factors such as inter-firm collaborators (Rosenfeld 1996), and desire to seek cost reduction and/or product differentiation (Porter 1998).

Besides the drivers of IT adoption, there are the factors that affect the IT adoption process. A couple of factors that impact the process of adopting IT often are the role of the top management or owner-manager of small businesses and the investment cost of IT. The owner-managers of SMEs make most of the decisions from daily operations to strategies and investments in the firm (Bruque and Moyano 2007). This also applies to decisions to adopt IT, from planning to implementing, followed by maintaining and upgrading the system. Studies have found the ownermanager's attitude towards IT and understanding of it matters (Bassellier et al 2003). A positive attitude and good understanding of IT was found to be positively correlated to the likelihood of adoption of IT and a successful one at that. Thong and Yapp (1995) examined 166 small businesses that adopted IT and found that managers who are highly innovative and have a positive attitude toward IT together with a skilled IT background are more likely to be successful in adopting IT. Using the Theory of Planned Behavior (Ajzen 1991) to explain and predict the decisions to adopt IT in small businesses, Harrison et al (1997) considered the variables of attitude, subjective norms, and perceived control in top management and found that executives decide to adopt IT for competitive purposes. It has also been found that the top managements' managing and administrative abilities contribute to the adoption process (Carson and Gilmore 2000). So, we can see that numerous studies have indicated that the characteristics, behavior, 
and frames of reference of top management or owner-managers affect all activities of the firm and the future of the business thus affecting adoption of IT.

Investment of financial resources in addition to time and other resources constitute an important factor enabling adoption of IT (Piccoli 2008). Financial commitment includes both direct and indirect costs. Direct costs include initial cost of software and hardware, the cost of training personnel, and maintaining the system. The indirect costs can have longer impacts and are often unforeseen by owner-managers of small businesses due to lack of experience with enterprise IT projects - in their development and/or operation, and also due to not being in communication with those who do have insights into the effects of IT because such professionals are not typically in the payrolls or in contract with small businesses. One long term cost is that adoption of IT is likely to bring about changes in work practices that if not planned and executed properly can lower productivity, for example if the employees do not know how to integrate the technologies into their job responsibilities and work procedures. Management time spent leading, planning, and organizing the integration of new and upgraded systems into current work practices is a significant indirect cost (Love and Irani 2004). Indirect costs also arise when management has to spend time revising, approving, and amending their IT strategies.

As we have discussed, there have been several empirical studies investigating the factors in IT adoption but these studies have generally focused on characteristics that relate to one or a limited number of functions in an organization. Also, several of them measure IT as a dichotomous variable - whether the business is computerized or not computerized. Anecdotal accounts from trade literature and several empirical studies suggest that the actual types of IT investments made SMEs appear to vary considerably. IT may be implemented in a comprehensive, firm wide fashion, or more selectively to support specific functions, or on an ad hoc basis to fix some particular problems or accomplish short-term goals such as to meet the contractual requirement of customers such as government agencies. Our literature survey shows that IT investment in small businesses is a multidimensional variable to go with the multidimensional nature of IT. Weil (1992) contends that IT is a multidimensional phenomenon and identifies three purposes - strategic, that is, IT investments aim to further the firm's competitive advantage and whose impact is reflected in market share, growth, sales growth, etc, transactional, that is, IT investments largely automate formerly labor intensive function areas, such as payroll and order entry, and informational, that is, IT investments enhance the effective dissemination and use of data for decision making, such as business intelligence systems to analyze and identify the more revenue generating customer segments. We suggest that before we can fully determine the impact of IT within small businesses and more precisely, within particular functions, we first need to isolate factors that have prompted these investments and also ascertain where these IT investments have been focused. To do this we present a series of research propositions, based on existing literature dealing with the relationship of several antecedents with types of IT investments that small businesses can make, and will present the results of an empirical study, when completed, that examines these propositions. When our research is completed, we shall also discuss the implications of our findings and suggest directions of future research. At this time, we offer some basic findings based on summary statistics.

\section{RESEARCH PROPOSITIONS}

Based on the review of literature on technology innovation and financial and managerial decision making in the context of small businesses, we develop the following propositions.

\section{Nature of IT Investments}

Consistent with Weill's (1992) broad definition of IT and the taxonomy of general motivations, IT investments in a business including small businesses serve multiple purposes - strategic, operational, and tactical. This suggests that IT investment will not be homogenous but will better be represented operationally as a multidimensional occurrence. Therefore, our initial proposition is:

Proposition 1: IT investment is a multidimensional occurrence for small businesses. 
Volume XII, No. 1, pp. 373-381, 2011

\section{Antecedents of IT Investments}

Literature suggests that IT changes the nature of relationships within and across firms (Levy et al 2001). Technology investments can facilitate the development of closer inter and intra firm relationships. It may be argued that in product-oriented firms, such as manufacturing firms, increased quality orientation may serve as an impetus for developing closer relationships externally with vendors and suppliers, and internally with other functional areas such as production and logistics, and for investment in IT. However, for service oriented firms, such as financial services, information itself may be a product. The degree to which information is present in a product or service in such businesses reflects the quality of the product. Increasing the informational content of a product or service will be the main impetus for any inter or intra organizational relations and for investment in IT. Thus product and service oriented firms may be varied in their motivations of investing in IT. Propositions 2 and 3 are stated as follows.

Proposition 2: IT investments will be positively influenced by a small firm's quality orientation in product-oriented firms.

Proposition 3: Small businesses that are more likely to use information as a product are likely to be positively influenced by IT investments.

Further, IT investments are often made to enhance the efficiency and accuracy in communication (Weill 1992; Corso et al 2003). Increased efficiencies may result in improved asset utilization through improved inventory turnover, receivables turnover, and fixed asset turnover. Typically, this would result in improved productivity leading to increased volumes, reduced costs, and improved customer relationships. Thus we propose:

Proposition 4: IT investments will be positively influenced by the small firm's desire to improve internal efficiency.

Anecdotal evidence as well as empirical findings (Lema and Durendez 2007) suggest that budgetary constraints are often important inhibitors of IT investments. Additionally, factors such as the availability of trained staff and adequate top management support (Bassellier et al 2003) also facilitate financial decision making regarding IT investments. Thus the existence of adequate financial resources, staff and executive support that demonstrate organizational willingness to commit would appear to be prerequisites to any IT investments (Jones et al 2006; Macpherson et al 2003). Consequently, we propose:

Proposition 5: IT investments will be positively influenced by the extent of the small firm's resources and commitment.

The firm's willingness to commit is largely dependent on the CEO/owner's outlook to innovations and risk taking attitude (Jones et al 2007; Thong and Yap 1995). The CEO's qualities are determinants of all financial decision making. This would also imply that the more knowledgeable the CEO/owner of a small business is about IT and its uses, the more willing she would be to adopt it (Bassellier et al 2003; Thong and Yap 1995). Hence we posit:

Proposition 6: Small businesses with more innovative CEOs are more likely to make financial investments in IT.

Proposition 7: Small businesses with CEOs who are more knowledgeable about IT are more likely to invest in IT.

Proposition 8: Small businesses with more technically skilled top management are more likely to invest in IT.

Mandates from governments can be pressures to implement or update IT systems - an example being the SarbanesOxley Act that was created to reform accounting procedures and protect investors from fraud. Gunasekaran et al (2006) reported about some studies finding a majority of their data samples in surveys had used legal and governmental requirements as a criterion in determining IT investments. Small firms can be expected to respond to relevant laws and regulations at the federal, state, and local government levels in order to achieve reporting compliance, for example to comply with sales and use taxes obligations or hazardous materials storage and handling requirements, or to take advantages of tax incentives. Thus we propose: 
Volume XII, No. 1, pp. 373-381, 2011

\section{Proposition 10: Governmental influence will impact IT investments in small firms.}

It has been argued that IT investments will be able to change the business environment by changing the industry structure and competition; create competitive advantages by giving new ways to businesses to influence their rivals; and spawn new businesses (Chaston and Mangles 2000). Thus, a small business in a more competitive environment may need to invest in IT to gain competitive advantage. Hence we propose:

Proposition 11: IT investments will be positively influenced by the small firm's competitive climate.

\section{RESEARCH METHODOLOGY}

The survey instrument was developed in several stages. An initial two-page survey was created using existing literature and was discussed with the small business council officials of a local chamber of commerce. Their input was used to develop a first draft of the more comprehensive instrument used in this study. The draft questionnaire was distributed to 8 small businesses who volunteered to fill it out and participate in an interview. Three of those businesses were interviewed after they completed the questionnaire to clarify respondent's understanding of the questions and responses and check for its clarity, readability, consistency, practicality, completeness, and validity. Results from those interviews were used to edit and clarify questions for the final survey instrument.

Multi-item scales were developed for each of the variables included in our research propositions. Single-item measures of relevant structural and contextual factors were also obtained for control purposes. We developed multidimensional constructs of IT which are composite indexes derived from multi-item scales related to each of these dimensions of IT use. Our independent variables represent contextual factors deemed to influence a small enterprise's decision to invest in IT. These measures are also composite indexes derived from multi-item scales related to each of threes contextual factors. Some additional single-item measures capture the demographics of the firm, for example, the firm size as indicated by the number of employees, number of years in business, annual revenue, and number of customers.

The target populations for the survey were small business databases owned by the chambers of commerce in three metropolitan regions - in Texas, Georgia, and Pennsylvania. The questionnaires were mailed directly to a single named owner or senior executive in the company and were mailed to all the small business members of the chambers of commerce that had a usable mailing address in the database. The mailing in the Texas based metropolitan area went to over 2,200 small businesses and 141 usable responses were received producing an approximately $6 \%$ usable response rate; the mailings in the Georgia based metropolitan area went to over 3,400 small businesses with 190 usable responses being received, giving an
Table 1

Sample characteristics

\begin{tabular}{lll}
\hline & $\mathrm{N}=526$ & Perc \\
\hline $\begin{array}{l}\text { Firm size by number of } \\
\text { employees }\end{array}$ & & \\
$\quad$ Less than 51 & 341 & 64.9 \\
$51-100$ & 47 & 8.9 \\
$101-150$ & 52 & 9.9 \\
$151-200$ & 44 & 8.3 \\
$201-250$ & 42 & 8.0 \\
& & \\
Respondents by job position & & \\
Owner & 311 & 59.2 \\
CEO & 340 & 64.7 \\
CIO & 25 & 4.7 \\
Partner & 168 & 32.0 \\
CFO & 234 & 44.5 \\
Other & 35 & 6.6
\end{tabular}

Turnover of firms

$\begin{array}{lll}\text { Less than } \$ 10 \mathrm{M} & 159 & 30.3 \\ \$ 11-20 \mathrm{M} & 257 & 48.8 \\ \$ 21-50 \mathrm{M} & 43 & 8.1 \\ \$ 51-100 \mathrm{M} & 37 & 7.0 \\ >\$ 100 \mathrm{M} & 31 & 5.8\end{array}$

Industry sectors

Accommodation and food

services

Agriculture

Construction

$27 \quad 5.2$

Health care \& Social

assistance

$58 \quad 11.0$

Information

$90 \quad 17.2$

$\begin{array}{lll}\text { Manufacturing } & 53 & 10.1\end{array}$

$\begin{array}{lll}\text { Retail trade } & 64 & 12.1\end{array}$

$\begin{array}{lll}\text { Other } & 113 & 21.4\end{array}$
Finance and Insurance $\quad 49 \quad 9.3$ 
Volume XII, No. 1, pp. 373-381, 2011

usable response rate of approximately 5.6\%; and in the Pennsylvania based metropolitan area, the usable response rate was about $6.2 \%$ based on the 195 usable responses received from among 3,100 small businesses who were contacted. The combined total usable surveys are 526 .

\section{PRELIMINARY DATA ANALYSIS}

Table 1 provides some sample characteristics about those SMEs that responded. Figure 1 displays the frequency of firm sizes by number of employees. Figure 2 displays the percentages of businesses by industry sectors. A large majority of the small firms are at a micro business level with $64.9 \%$ having 50 employees or less. A vast majority of the responders were the CEO and/or the owner (64.7\% and 59.2\%). The survey question allows choosing as many job positions as the responder needs. An overwhelming majority of businesses $-79.9 \%$ - had a turnover (volume of business transacted) of less than USD 20 million with $30.3 \%$ being less than USD 10 million. The industry sectors have been classified by the North American Industry Classification System (NAICS) code which has largely replaced the older Standard Industrial Classification (SIC) system. The top two categories were healthcare and social assistance services and construction firms. The healthcare and social assistance category included childcare facilities and small businesses providing at-home nursing and home assistance to elderly population.

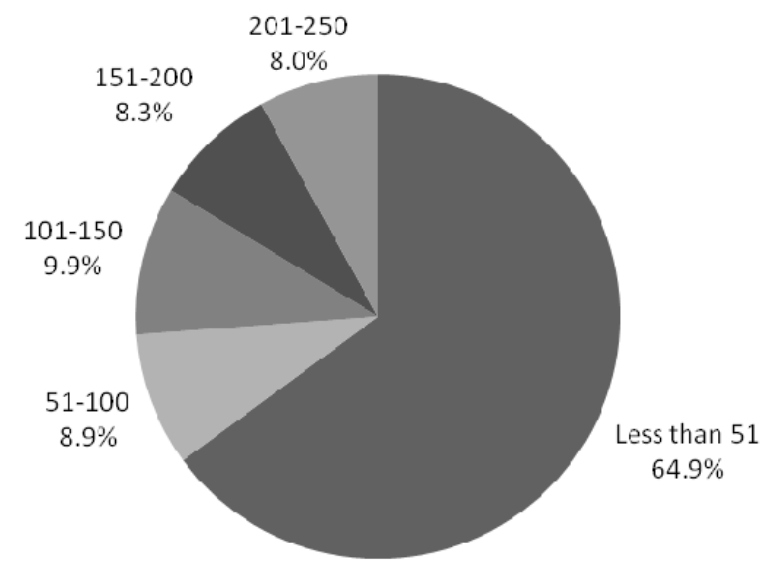

Figure 1 Firm size by number of employees

Twenty eight percent of the businesses are owned by African-Americans and thirty nine percent by Hispanic Americans. These are high numbers compared to the percentages of minorities in the general population, and that

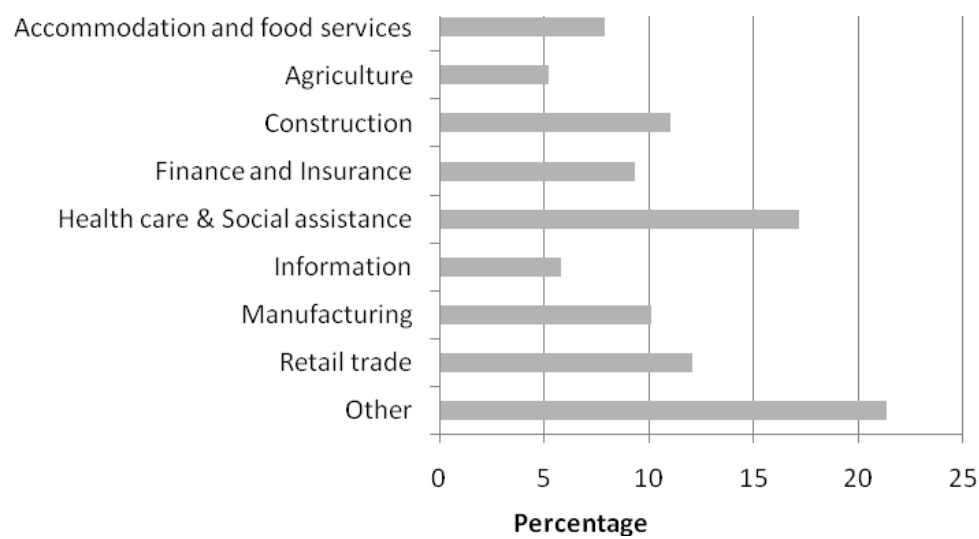

Figure 2 Percentages of businesses by industry sectors 
may be explainable to the locations where the survey responses came from. The three regions where the samples came from are metropolitan areas with two being in the south, and all these areas have a larger share of minority population compared to the overall population. Women make up $38 \%$ of the majority shareholders. Companies have been in the business on average 12.5 years and have been using IT for an average of 7.1 years. Respondents having a 4 -year college degree or post baccalaureate education made up 53\% of the respondents while $40 \%$ had either some college education or a 2-year degree. The respondents fall in the age group of 21 to 72 years, thus covering most of the working years range of a typical adult. The majority of the responders have had computer training ranging from one month to one year that they underwent mostly in high school and college, with a small number having sought training at professional training centers. This provides a picture of small business leaders being well educated and computer-skilled to face the challenges of the changing business environment.

A firm owns 8 computers on average with the vast majority having them wirelessly networked and with internet access. The top three functions supported by IT were accounting, sales, payroll, and word processing followed by billing, budgeting, and inventory control. The vast majority of the information systems $-83 \%$ - are based on offthe-shelf packages while $14 \%$ had their systems developed, and some companies used both approaches. The fact that many needed to get systems developed indicates that there are specific needs of small businesses that cannot be met by packaged software.

Detailed data analysis will be carried out beginning with testing each construct for reliability using Cronbach's coefficient alpha $(\alpha)$. An $\alpha$ value of 0.70 or above indicates a reliable measurement instrument. The construct of the multi-item scale will be assessed where the retained cases will be examined for missing values by replacing them using the substitution by random assignment within groups procedure (Kim and Curry 1977). The unidimensional aspect of the instrument items will be assessed by including all the multi-item scales in the same confirmatory factor model. We will report the factor loading and associated fit statistics. If the fit indices show an adequate fit to the data, which we expect, then we will conclude that each scale was measuring a single latent construct.

Having determined unidimensionality and the construct reliability of the multi-item scales, we plan to estimate discriminant validity by creating a series of additional models in which one inter-trait correlation will be constrained to unity in each model. If the differences in chi square value between the original measurement model and each of the additional models are found to be significant, then it will provide evidence of discriminability. Finally, using composites of the scales along with the other measures, we plan to test our research propositions using ordinary least squares regression analysis.

\section{CONCLUSIONS AND LIMITATIONS}

Small businesses play an important role in the economy because it creates the biggest number of jobs and contributes to the socio-economic development in a major way. Being the backbone of the economy, it is important for SMEs to become more competitive. To accomplish this, it is imperative for SMEs to incorporate IT as much as possible in their businesses. Sooner the SMEs realize the benefits of IT and work towards removing the barriers holding them back from adopting IT, the quicker they will become more competitive and be able to innovate. On successfully integrating IT into their businesses, SMEs can be expected to make significant economic gains that will benefit not only the businesses but also the society as a whole through job growth and increase in the earning capacity of the population.

On completion, this study hopes to address all the research objectives set forth by investigating the relationship of several antecedents with types of IT investments that small businesses can make through a questionnaire-based survey. It is hoped that the findings will provide the SMEs with an opportunity to assess themselves on the various issues affecting their state of adoption of IT and guide them to make sound decisions in adopting IT. Empirical findings from this study are expected to add to the body of literature giving a clearer understanding of why SMEs adopt IT and what factors contribute to the process of improving the adoption of IT by SMEs.

Among the limitations of the study, generalizations from this study should be done with caution because the sample base is limited to just a few urban areas. The choice of the areas may influence the type of industry sectors and the number of samples in those industry sectors as well as the distribution of the ethnicity of the business owner- 
managers represented in the sample. A typical limitation of survey research exists in this study as well, that being only those interested in the research topic are likely to complete and return the questionnaire reflecting perhaps those owner-managers who have a certain attitude towards adoption IT thus skewing the findings a certain way. Future research can involve addition of new constructs such as owners' personal characteristics, organizational culture, role of consultants in promoting IT adoption, and IT abilities of the company's employees. A larger sample base will overcome the aforementioned limitations, and a longitudinal study could reflect on the reliability of the variables used in the study as well as the role of timeframe on the adoption of IT.

\section{REFERENCES}

1. Ajzen, I. (1991). The theory of planned behavior. Organization Behavior and Human Decision Processes, 50, 179-211.

2. Anderson, J., \& Schwager, P. (2003). SME Adoption of Wireless LAN Technology: Applying the UTAUT Model. In Proceedings of the Southern Association for Information Systems (pp. 39-43).

3. Andries, P. and Debackere, K. (2006). Adaptation in new technology-based ventures: insights at the company level. International Journal of Management Reviews, 8(2), 91-112.

4. Bassellier, G., Benbasat, I. and Reich, B. (2003). The influence of business managers' IT competence on championing IT. Information Systems Research, 14(4), 317-336.

5. Bruque, S. and Moyano, J. (2007). Organisational determinants of information technology adoption and implementation in SMEs: the case of family and cooperative firms.

6. Technovation, 27(5), 241-53.

7. Burca, S., Fynes, B. and Marshall, D. (2005). Strategic technology adoption: extending ERP across the supply chain. Journal of Enterprise Information Management, 18(4), 427-440.

8. Burgess, S. (2002). Information technology in small business: issues and challenges. In Burgess, S. (Ed.), Managing Information Technology in Small Business: Challenges \& Solutions (pp. 1-17). Hershey, PA: Idea Group Publishing.

9. Caldeira, M. M., \& Ward, J. M. (2002). Understanding the successful adoption and use of IS/IT in SMEs: an explanation from Portuguese manufacturing industries. Information Systems Journal, 12(2), 121.

10. Carson, D. and Gilmore, A. (2000). SME marketing management competencies. International Business Review, 9(3), 363-382.

11. Chaston, I. and Mangles, T. (2000). Business networks: assisting knowledge management and competence acquisition within UK manufacturing firms. Journal of Small Business and Enterprise Development, 7(2), 160170.

12. Corso, M., Martini, A., Pellegrini, L. and Paolucci, E. (2003). Technological and organizational tools for knowledge management: in search of configurations. Small Business Economics,

13. 21(4), 397-408.

14. Gunasekaran, A. and Ngai, E.W.T. and McGaughey, R.E. (2006). Information technology and systems justification: A review for research and applications. European Journal of Operational Research, 173(3), 957983.

15. Harrison, D., Mykytyn, P.J. and Riemenschneider, C. (1997). Executive decisions about adoption of information technology in small business: theory and empirical tests. Information Systems Research, 8(2), 171195.

16. Huang, C. D., Hart, P., \& Wiley, M. (2004). Factors Characterizing IT Use in SMEs: An Exploratory Study. In Proceedings of the Innovations through Information Technology Conference, New Orleans, LA (pp. 12291230). Hershey, PA: Idea Group.

17. Jones, O., Macpherson, A., Thorpe, R. and Ghecham, A. (2007). The evolution of business knowledge in SMEs: conceptualizing strategic space. Strategic Change, 16, 281-294.

18. Kim, J. and Curry, J. (1977). The treatment of missing data in multivariate analysis. Sociological Methods and Research, 6, 215-239.

19. Lema, D. and Durendez, A. (2007). Managerial behaviour of small and medium-sized family businesses: an empirical study. International Journal of Entrepreneurial Behaviour \& Research, 13(3), 151-172.

20. Levy, M., Powell, P. and Yetton, P. (2001). SMEs: aligning IS and the strategic context. Journal of Information Technology, 16(3), 133-44. 
Volume XII, No. 1, pp. 373-381, 2011

21. Love, P., and Irani, Z. (2004). An exploratory study of information technology evaluation and benefits management practices of SMEs in the construction industry. Information and Management, 42, 227-242.

22. Macpherson, A., Jones, O., Zhang, M. and Wilson, A. (2003). Re-conceptualising learning spaces: developing capabilities in a high-tech small firm. Journal of Workplace Learning, 15(6), 259-270.

23. Matthews, P. (2007). ICT Assimilation and SME Expansion. Journal of International Development, 19, 817 827.

24. Oakey, R.P. and Cooper, S.Y. (1991). The relationship between product technology and innovation performance in high technology small firms. Technovation, 11(2), 79-92.

25. Piccoli, G. (2008). Information Systems for Managers, Hoboken, NJ: Wiley.

26. Proudlock, M. (1999). IT adoption strategies: best practice guidelines for professional SMEs. Journal of Small Business and Enterprise Development, 6(3), 240-252.

27. Raymond L., Bergeron F., Blili S. (2005). The assimilation of E-business in manufacturing SMEs: determinants and effects on growth and internationalization. Electronic Markets 15(2), 106-118.

28. Rosenfeld, S.A. (1996). Does cooperation enhance competitiveness? Assessing the impacts of inter-firm collaboration. Research Policy, 25(2), 247-263.

29. Siggelkow, N. and Levinthal, D. (2005). Escaping real (non-benign) competency trap: linking the dynamics of organizational structure to the dynamics of search. Strategic Organization, 3(1), 85-115.

30. Summary of Size Standards by Industry - SBA.gov. (2011). Retrieved July 3, 2011, from $\mathrm{http}: / / \mathrm{www}$. sba.gov/content/summary-size-standards-industry

31. Tan, K. S., Chong, S. C., Lin, B., and Eze, U. C. (2010). Internet-based ICT adoption among SMEs: Demographic versus benefits, barriers, and adoption intention. Journal of Enterprise Information Management, 23(1), 27-55.

32. Thong, J. and Yap, C. (1995). CEO characteristics, organizational characteristics and information technology adoption in small businesses. Omega - The International Journal of Management Science, 23(4), 429-42.

33. Weill, P. (1992). The relationship between investment in information technology and firm performance: a study of the valve manufacturing sector. Information Systems Research, 3(4), 307-333.

34. Wolcott, P., Qureshi, S. and Kamal, M. (2007). An Information Technology Therapy Approach to Microenterprise Adoption of ICTs. In Proceedings of the Americas Conference on Information Systems (AMCIS).

35. Wymer, S. and Regan, E. A. (2011). Influential factors in the adoption and use of E-Business and E-Commerce information technology (EEIT) by small \& medium businesses. Journal of Electronic Commerce in Organizations (JECO), 9(1), 56-82.

36. Xu, M., Rohatgi, R., \& Duan, Y. (2007). E-Business adoption in SMEs: Some preliminary findings from electronic components industry. International Journal of E-Business Research, 3(1), 74-90 